\title{
Ligand-Independent Ion Channel Activation
}

National Cancer Institute

\section{Source}

National Cancer Institute. Ligand-Independent Ion Channel Activation. NCI Thesaurus.

Code C88470.

A process that involves interactions between an intrinsic membrane molecule and an electrochemical gradient across a membrane, often a voltage or a pH gradient. Such interactions may activate or deactivate an ion channel in the membrane, and constitute the basis of nerve conduction of impulse. 